\title{
Chapter 28 \\ Safe Snow and Ice Construction to Arctic Conditions
}

\author{
Kai Ryynänen
}

\begin{abstract}
Snow and ice are the key elements in winter tourism, especially in the Nordic countries. Finnish Lapland has a multitude of attractions that provide visitors unique arctic experiences in snow and ice constructed environments. In Finland, snow and ice operators and builders are usually small and medium size enterprises (SME). There is lack of knowledge on using snow and ice as construction material. This article will provide basic knowledge on using snow and ice as construction material in safe structures.
\end{abstract}

\subsection{Introduction}

Snow and ice are pure natural materials of the Arctic area. They can be used as a building material within certain boundary conditions. Due to its crystal structure, snow - especially artificial snow - is mainly suitable for compressive structures. The density, i.e., volumetric weight of snow in a structure changes during the entire service life of the structure (RIL 2001).

Detailed information on the material properties of snow and utilisation of these properties is available in literature. The material property values that are used in designing snow structures are chosen case by case by the structural engineer. The property values are affected by temperature, snow quality and the load of the snow and of the built structure (RIL 2001). The special properties of snow and ice materials must be taken into consideration in calculations and in construction. The structural safety against breakage, falling over and deformation should be analysed during planning process.

Ice has a special property; its crystal structure does not remain constant under loading or thawing (Ryynänen 2011). The properties of ice change according to the temperature of the ice. The structural properties of ice are weakest at $0{ }^{\circ} \mathrm{C}$. As the

\footnotetext{
K. Ryynänen ( $ه)$

Lapland University of Applied Sciences, Rovaniemi, Finland

e-mail: kai.ryynanen@lapinamk.fi
} 
temperature of ice rises, its strength decreases and its modulus of elasticity, shear modulus and creep strain grow (Kilpeläinen and Mäkinen 2003).

Slush can also be used as a building material in snow and ice construction. Slush is a mixture of snow and water. Snow and ice structures in which the amount of water added during the construction phase exceeds $5 \%$ of the amount of snow used can be called slush structures. The proportion of the different components in the mixture is unevenly distributed (Ryynänen 2011).

\subsection{Designing Snow and Ice Structures}

The basic principle in designing snow and ice structures is to ensure the safety of the people who are using the structure. The construction guidelines only deal with structures that are large enough or used in a way to require an official permit for their construction. A person who is using calculations done with the formulas presented here must be a professional in the field of construction and hold sufficient competence in structural design (RIL 2001). In Finland, structural design complies with the regulations and guidelines provided in the Finland's National Building Code, issued by the Ministry of the Environment and the Eurocode Standards ratified by Finland (Ministry of Environment 2001, 2002, 2004).

The special properties of snow and ice materials must be taken into consideration in calculations and in construction. The following design parameters must be analysed when designing load-bearing structures:

- Ultimate limit state calculations; these indicate structural safety against breakage and falling over.

- Serviceability limit state calculations; these indicate structural safety against deformation.

The partial coefficient of safety -method is used in the structural calculations. Use of partial coefficients of safety in the calculations produces reliable limit values, so that structural deformations and changes in loading during the service life can be predicted (RIL 2001).

The impact of weather conditions on snow and slush structures must be assessed. In the Finnish construction guidelines, there are instructions how to assess weather conditions. If the construction site and structures are the same every year, weather condition information from previous years, if based on sufficiently reliable measurements, can be used to assess the structural behaviour (RIL 2001).

In serviceability limit state analysis, limit values are set for the structure. If these values are reached or exceeded, the use of the snow and ice structure must be suspended or terminated. Limit values in the serviceability limit state are tilt, sag, window and door functionality, and retention of the original structure (RIL 2001; Ryynänen 2011) as presented in Fig. 28.1. 

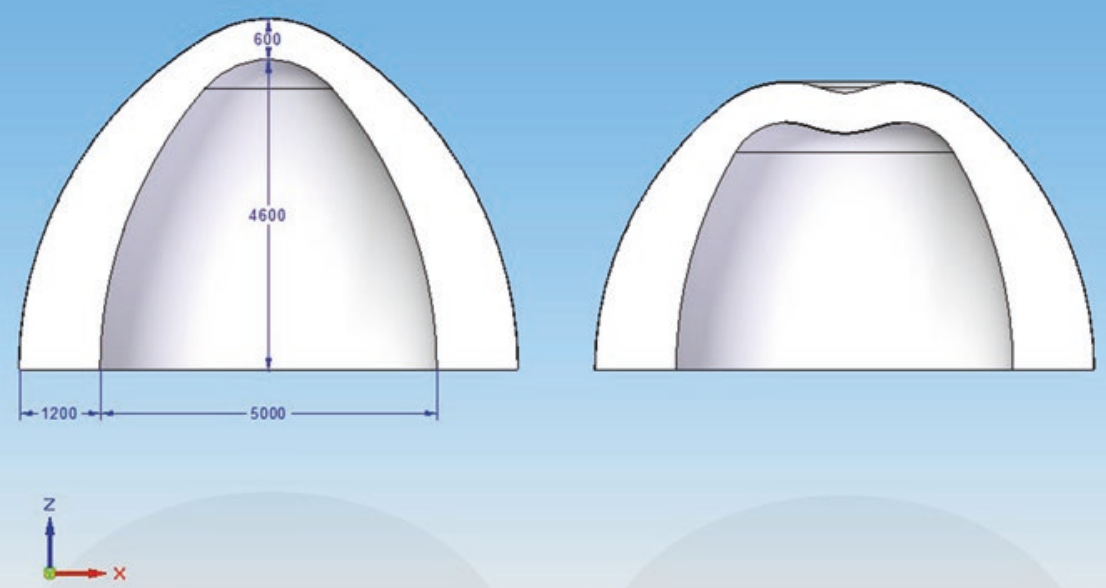

Fig. 28.1 Retention of the original structural shape in snow, ice and slush structures (Ryynänen 2011)

\subsection{Designing of Snow Structures}

In snow structures, the structural calculations follow the guidelines provided in RIL (2001). When using the guidelines, the density of snow is between 400 and $820 \mathrm{~kg} /$ $\mathrm{m} 3$. Deformation of snow should be taken in the account. By using snow as construction material, compression structures can be made (Ryynänen 2011). For example, a snow structure designed according to RIL guidelines is shown in Fig. 28.2.

\subsection{Designing of Ice Structures}

The loads of ice structures are calculated as described in the Snow Structures guidelines RIL 218-2001 (RIL 2001). The density of the ice used in calculations is $920 \mathrm{~kg} / \mathrm{m}^{3}$ regardless of whether natural or artificial ice is used. The thawing effect of the sun and the eroding effect of wind must be taken into consideration in specifying structural thicknesses (Ryynänen 2011). Ice structures are designed at a temperature of $0{ }^{\circ} \mathrm{C}$, because various studies have indicated that the material properties of ice are most reliable and adequate safety during the service life is achieved (for example the tilt and minimum thickness). Ice structures can be designed by using pieces of ice or by freezing (Ryynänen 2011). 


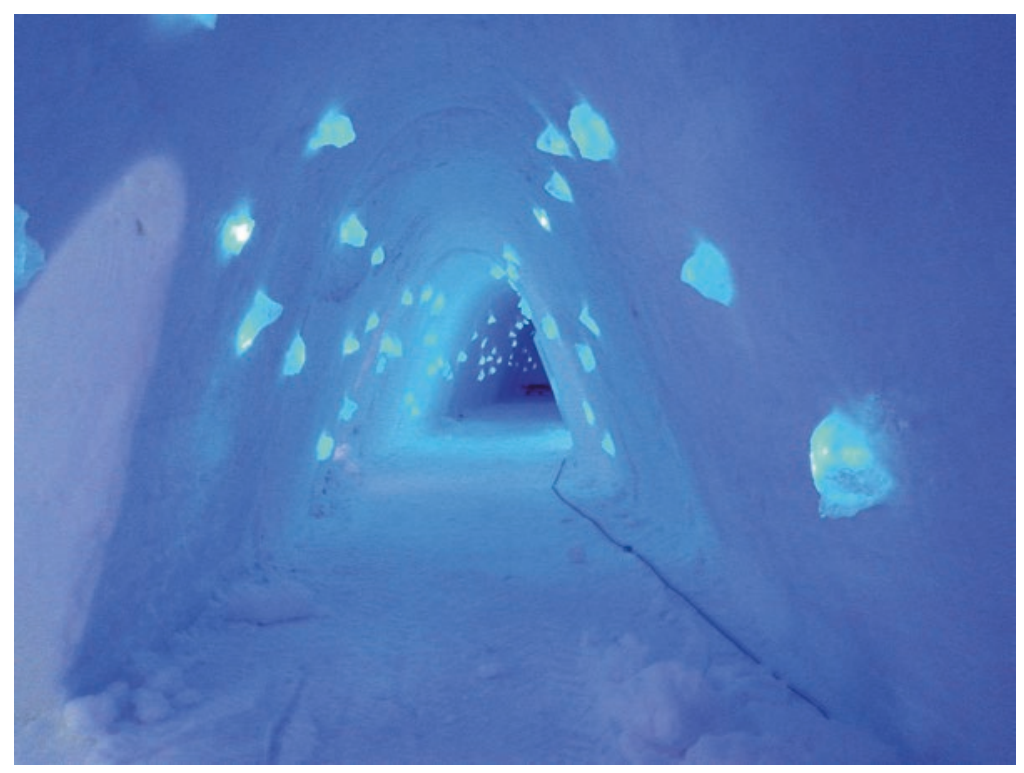

Fig. 28.2 Arch snow tunnel (Photograph: Kai Ryynänen 2011)

\subsection{Designing of Slush Structures}

Loads of the slush structures are calculated as described in Ryynänen (2011). Changes in tensions and deformation which occur during the service life of the slush structure calculated according to the RIL 218-2001 guidelines.

In Finland, construction of buildings or structures intended for professional use - such as in the tourism industry - requires a planning or building permit. This especially applies to cases where structures are constructed from snow or ice and people will be underneath or inside the said structures during their service life. In Finland, the building supervision authority specifies the necessity and type of permit. The objective is always to ensure the safety of the users of the structure (Ryynänen 2011).

The building permit may be granted for a fixed-term or temporary building and for one time or for a five-year period, for example. The designer of a snow and ice building must be a sufficiently competent person with necessary training in the sector and experience in similar design jobs. Finnish authorities who supervise construction and use have specified that the following guidelines must be followed in snow and ice structures (Ministry of Environment 2001, 2002; Ryynänen 2011). 


\subsection{Safe Use of Snow and Ice Buildings}

In case of a fire or other emergency, it must be possible to exit the building safely. For that, the building must have an adequate number of suitably situated, sufficiently wide and easily navigable exits. Structures used as lodging or meeting rooms must be equipped with exit signs. Maps of exit routes must be situated in visible places in the building. In addition, every evacuation area in the building that is occupied by employees or other persons more than temporarily must have at least two separate appropriately situated exits (Pitkänen 2003).

Smoke alarms must be installed to all bedrooms of the snow and ice buildings (Pitkänen 2003) and those fire detectors should be designed for cold climate conditions. If necessary, the building must be equipped with adequate and appropriate fire extinguishing equipment.

Snow and ice buildings are usually places to where everyone must have access. The rooms must be designed so they can be used by disabled persons. Thus, attention must be paid to travel routes, ramps and toilet facilities (Ministry of Environment 2004). Attention must be paid to at least the following items in connection with snow and ice construction: stairs, handrails, guardrails, adequate lighting and antislipping measures (RIL 2001).

\subsection{Monitoring of the Structures During Their Service Life}

Snow and ice structures must be monitored during their service life. Monitoring includes both daily maintenance inspections and long-term monitoring, such as the measurement of deformation. In Finland, a separate operating and safety plan is compiled for each snow and ice building site as a part of its construction (Ryynänen 2011).

Deformation of snow and ice structures must be monitored during the structure's entire service life. The deformation measurement points and measurement intervals for each load-bearing structure must be specified in the building plans. The hardness of the structure must also be monitored during its service life by measuring it at regular intervals. Hardness is monitored with measurements and by visual observations. If one of the limit values (for example whether the structure has sagged or tilted, or fractured/ collapsed) is reached during the service life of a snow and ice structure, the use of the structure must be suspended. If the suspension lasts for a long time or the cause cannot be eliminated, dismantling of the structure should be considered (Ryynänen 2011).

The user and the party responsible for maintaining the snow and ice structure have to specify the time when the structure will be dismantled. The authorities may also appoint an external party who specifies the conditions for dismantling of the structure, for example in sites that involve special procedures such as break down roofs and close entrance using snow or ice (Ryynänen 2011). 


\subsection{Next Steps in Snow and Ice Construction}

There is a need for co-operation between the countries such as Finland, Sweden, Norway, Canada, Japan and China that have snow and ice constructions. Ideally, they should build up a network of snow and ice research institutions, universities and snow and ice companies. One aim of such network would be to identify the similarities in the general designing and construction rules between the different countries. Also, there is a need for more research, for example, in the field of ice physics and slush construction, as well as in creation of new types of snow and ice structures.

New learning environments should be developed through innovation activities and co-operation between educational institutions, for example in a form of joint courses in snow and ice construction and snow physics. In the future, attention should also be paid to develop new innovations in the snow and ice construction and to strengthen the opportunities for SMEs, especially in the snow construction and tourism-based businesses.

\section{References}

Kilpeläinen M, Mäkinen S (2003) Structural properties of ice. NorTech Oulu report 2/2003. University of Oulu, Oulu

Ministry of the Environment (2001) National building code. F2 building's operational safety. Regulations and guidelines 2001, Helsinki

Ministry of the Environment (2002) National building code. A2 building's designers and designs. Regulations and guidelines 2002, Helsinki

Ministry of the Environment (2004) National building code. F1 accessible building. Regulations and guidelines 2004, Helsinki

Pitkänen M (2003) Building supervision's perspective of snow construction, safety factors. City of Kemi Building Supervision, Kemi

RIL Finnish Association of Civil Engineers (2001) Design and construction guidelines for snow structures. RIL 218-2001. General copy - Painopörssi, Helsinki

Ryynänen K (2011) Snow and ice construction guide, hints for authorities - guidelines for builders. Rovaniemi University of Applied Sciences, report C 27

Open Access This chapter is licensed under the terms of the Creative Commons Attribution 4.0 International License (http://creativecommons.org/licenses/by/4.0/), which permits use, sharing, adaptation, distribution and reproduction in any medium or format, as long as you give appropriate credit to the original author(s) and the source, provide a link to the Creative Commons license and indicate if changes were made.

The images or other third party material in this chapter are included in the chapter's Creative Commons license, unless indicated otherwise in a credit line to the material. If material is not included in the chapter's Creative Commons license and your intended use is not permitted by statutory regulation or exceeds the permitted use, you will need to obtain permission directly from the copyright holder.

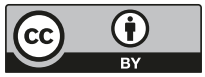

